\title{
SECOND LANGUAGE PERCEPTION OF ENGLISH VOWELS BY PORTUGUESE LEARNERS: THE EFFECT OF STIMULUS TYPE
}

\author{
Anabela Rato ${ }^{1 \times}$ \\ ${ }^{1}$ University of Toronto, Toronto, Canada \\ Angélica Carlet ${ }^{* *}$ \\ ${ }^{2}$ Universitat Internacional de Catalunya, Barcelona, Spain
}

\begin{abstract}
The study investigated the effect of stimulus type on L2 English vowel perception and it also examined the relation between subject factors and L2 learners' performance. Twenty-nine adult Portuguese learners of English were tested on six English vowels (/i: I $\varepsilon$ æ 3 : $\Lambda /$ ) with two tasks, differing in stimulus type: real and pseudo words. The language background data was collected with a questionnaire. Results confirmed the Portuguese learners' difficulties in accurately categorizing the target vowels, particularly when identifying the L2 vowel sounds embedded in pseudo words, which suggests that L2 phonological categories may be established after lexical forms. Furthermore, a significant correlation was found between L2 language use and accurate perception of four of the target vowels, which indicates that the more frequently learners use the target language, the more accurate is their L2 English vowel perception. Keywords: L2 Speech Perception; English Vowels; Portuguese Learners; Stimulus type
\end{abstract}

\footnotetext{
"Assistant professor and the associate chair of Portuguese studies at the department of Spanish and Portuguese, university of Toronto, Canada. She is also the chair of the Canadian association of teachers of Portuguese. She received her Ph.D. in Language Sciences and her Master Degree in English language, literature, and culture from the University of Minho, Portugal. Her research interests include second language speech acquisition, speech perception and production, and phonetic training. Email: anabela.rato@utoronto.ca. ORCID: http:// orcid.org/0000-0001-7822-8580.

" Professor of English linguistics and head of English at the Faculty of Education at Universitat Internacional de Catalunya (UIC), in Barcelona, Spain. She holds a Ph.D. in English philology and a Master's Degree in second language acquisition from the Universitat Autònoma de Barcelona (UAB). The influence of one's native language phonology in the acquisition of a second language constitutes the main area of her research interest along with the effect of formal instruction and stay abroad programmes on participants' oral skills. Her more relevant publications can be found at https://www.researchgate.net/profile/Angelica_Carlet/research. E-mail: acarlet@uic.es. ORCID: 0000-0001-8411-4731.
} 


\section{Introduction}

Research has shown that difficulties in the acquisition of non-native vowels may hinder the successful mastering of second language (L2) phonology by adult learners (Strange, 2007). English vowel sounds have been widely reported to be challenging for adult learners with different L1 backgrounds. Several studies on L2 English vowel acquisition by L1 speakers of different Romance languages with small vowel inventories such as Spanish (Aliaga-Garcia, 2010, 2017; Carlet \& Cebrian, 2015; Carlet, 2017; Cebrian, 2006; Cebrian, Mora \& Aliaga-Garcia, 2010; Flege, Bohn, \& Jang, 1997), Italian (Flege, MacKay, \& Meador, 1999; Flege \& MacKay, 2004) and Portuguese (Nobre-Oliveira, 2007; Rato, 2018; Rato, \& Rauber, 2015; Rato, 2014; Rato, Rauber, Soares, \& Lucas, 2014, Rauber, 2010; Rauber, Escudero, Bion \& Baptista, 2005) have revealed that the perception of the larger inventory of English L2 vowels is difficult due to an L2-to-L1 mapping issue (Bohn, 2017), that is, to how learners perceptually map the vowel sounds of the target language onto the vowel categories of the native language. Current models of L2 speech learning such as the Speech Learning Model (SLM, Flege, 1995) and Perceptual Assimilation Model (PAM-L2, Best \& Tyler, 2007) propose that the perceptual similarity between L1 and L2 vowels is one of the most important predictors of difficulty/ease in L2 vowel learning, with more target-like acquisition expected to occur when the L2 sound is perceived as different to the existing L1 sounds. Perceptual biases caused by L2-to-L1 mapping patterns seem to explain adult Portuguese learners' failure to discriminate the English vowel contrasts: / $/ \varepsilon /-/ \mathrm{I} /, / \varepsilon /-/ \mathfrak{x} /, / \mathrm{d} /-/ \Lambda /, / \mathrm{u} /-/ \mho /$ (Flege, 1994, as cited in Flege, 1995) and difficulties in both perception and production of $/ \mathrm{i} /-/ \mathrm{I} /, / \varepsilon /-/ \mathfrak{x} /$, and $/ \mathrm{u} /-/ \mho /$. The English vowels $/ \mathrm{I} /, / \mathfrak{e} /$, and $/ \mho /$ tend to be assimilated to Portuguese $/ \mathrm{i} /, / \varepsilon /$, and $/ \mathrm{u} /$ and no distinction between the two vowels of each pair is made due to their high degree of perceived cross-linguistic phonetic similarity (Rato \& Rauber, 2015; Rato, 2014; Rato et al., 2014; Rauber, 2010).

Second language speech acquisition is, however, a complex process that involves not only linguistic factors such as cross-linguistic influence (CLI), but also many interrelated variables pertaining to the learner. Therefore, difficulty in perceptually distinguishing and categorizing L2 vowels arises from the interaction of several factors. On one hand, internal factors such as age of onset of learning (AOL), and native language (L1) background, and on the other hand, external factors such as language use, length of formal instruction, learning context, and input may influence the development of L2 phonology (Piske, 2007). In addition, L2 vocabulary size has found to be associated with the ability to perceive and produce non-native sounds (Bundgaard-Nielsen et al., 2012).

The objectives of this study were to further contribute empirical data to the research on second language perception of English vowels by native European Portuguese speakers. Previous studies focused on phono-lexical mapping of L2 vowels, i.e., on the perception of L2 vowel phonemes presented in real words. This study explores the effect of stimulus type by including a comparison of 
vowel perception in real and pseudo words to investigate prelexical phonological categorization. It also aimed to examine which learner factors - age of learning, length of formal instruction, target language use, and vocabulary size - predict the perceptual performance of learners in L2 vowel identification.

\section{Review of Literature}

\subsection{Factors influencing L2 speech acquisition}

The outcomes of L2 phonological development are determined by the interaction of various factors related to both the learner and the learning context. Extrinsic factors include learners' L2 experience, viz. age of onset of L2 learning (AOL), length of residence (LOR) in an L2-speaking environment and/or length of formal instruction (LFI), quantity and quality of L2 input, amount of L2 use; and intrinsic factors consist of individual differences such as motivation, memory, and language learning aptitude (Moyer, 2013; Piske, 2007). In a large number of studies, learner variables affecting L2 speech performance both in perception and production have been examined (e.g., Flege, 1995; Flege \& Liu, 2001; Flege, Frieda, \& Nowaza, 1997; Flege, Munro \& MacKay, 1995a, 1995b; Piske, MacKay \& Flege, 2001; Rauber, Rato, \& Silva, 2010). The findings indicate that success in L2 speech learning is strongly influenced by four factors that interrelate with each other: age of L2 learning, amount of L1 and L2 use, quantity and quality of L2 input, and formal instruction in the perception and production of L2 sounds (Piske, 2007).

Age of onset of learning (AOL) is widely cited as the main neurobiological predictor of success in L2 phonology learning, and there is widespread agreement on the premise "the earlier, the better". However, research has not only shown that a low AOL does not automatically lead to native-like L2 speech (Flege, Frieda, \& Nowaza, 1997), but it has also revealed that even speakers who begin learning an L2 after the age of 12 may still learn to speak the target language without a foreign accent (Flege, Munro, \& MacKay, 1995b), since the ability to learn non-native sounds is available throughout a learner's lifespan. Language use has also been identified as one of the factors that have a substantial influence on L2 pronunciation (e.g., Jia, Strange, Collado \& Guan, 2006; Flege et al., 1995b; Flege et al., 1997; Piske, MacKay \& Flege, 2001). Jia et al. (2006) investigated the perception and production of Mandarin speakers learning L2 English in vowel contrasts $/ \mathrm{i}$-I/ $/ \varepsilon-æ /, / \Lambda$ - $\mathrm{a} /$ and found a significant positive effect on use. Flege et al. (1995b) reported that language use accounted for $15 \%$ of the variance in the foreign accent ratings obtained for native Italian immigrants to Canada. Two groups of early bilinguals from this study, matched for AOL in Canada but differing significantly in L1 use (3 vs. 36\%), were later investigated by Flege et al. (1997). The bilinguals who used their L2 more frequently had less strong foreign accents than those who used their L2 more seldomly. Piske et al. (2001) examined late bilinguals differing in L1-L2 language use and reported that the language use effect was also found in late bilinguals, suggesting that 
ultimate attainment in L2 speech acquisition is also determined by language use patterns. Quantity and quality of the input the L2 learners receive also have a major effect on L2 speech learning. Flege and Liu (2001) compared groups of Chinese learners of English differing in LOR in the United States, half of whom received a large amount of native-speaker input in English, while the other half had reduced exposure to input provided by native speakers of English. Although LOR differences in perceptual performance were found in the group with large exposure to native English input, no such differences were found in the group with reduced exposure to English. Thus, the authors inferred that LOR may not itself lead to L2 speech development and that it may provide a good index of L2 input only for those learners who frequently have contact with native speakers of the target language. In the context of a formal language classroom, this finding suggests that significant progress in the development of L2 speech may be only possible if learners are exposed to a substantial amount of high-quality input. Research investigating the influence of formal L2 classroom instruction on L2 speech acquisition has revealed that instructional factors have little or no effect on accuracy of L2 pronunciation (Flege, MacKay \& Meador,1999; Flege \& Fletcher, 1992; Carlet \& Souza, 2008; Rauber, Rato, \& Silva, 2010). For example, Rauber, Rato and Silva (2010) conducted a longitudinal study which examined the learning of English vowels by Mandarin speakers during an eight-month upper-intermediate EFL course that included explicit pronunciation instruction, but no improvement was reported in the production and perception of English vowels. Carlet and Kivistö-de-Souza (2008), however, found improvement in L2 vowel perception but not in production, after an eight-week formal instruction including explicit pronunciation instruction. Flege and Fletcher (1992) reported a significant influence of number of years of English instruction on L2 pronunciation accuracy. However, it only accounted for $5 \%$ of the variance in the foreign accent ratings of Spanish learners of English. Although there is little evidence that amount of formal instruction affects degree of L2 foreign accent, research has shown that if L2 classroom teaching involves intensive and adequate (segment-focused) training in the perception and production of non-native sounds, it has a larger effect on L2 phonological acquisition (Kissling, 2014; Lord, 2005; Rato, 2014; Rato et al., 2014.

In addition, a measure of $\mathrm{L} 2$ language proficiency that has been found to be associated with L2 speech learning is vocabulary size. Learners with larger L2 vocabulary sizes seem to assimilate and distinguish L2 sounds more accurately (Bundgaard-Nielsen, Best \& Tyler, 2011a, 2011b) and produce more intelligible vowel sounds (Bundgaard-Nielsen, Best, Kroos \& Tyler, 2012). BundgaardNielsen and her colleagues suggest that improvement in L2 speech perception and production during the early stages of L2 immersion may be positively associated with an expanding L2 vocabulary triggered by the need to decode and comprehend L2 speech rather than only perceive L2 speech on the basis of its phonetic (dis)similarities to the L1. Bundgaard-Nielsen, Best, and Tyler, (2011a, 2011b) found that Japanese L2 learners of English with larger English 
vocabularies more consistently identified L2 vowels than learners with smaller L2 vocabularies at an early point in L2 immersion, which confirmed their hypothesis that L2 vocabulary size is associated with L2 speech perception in adult L2 learners. However, the longitudinal study (Bundgaard-Nielsen, Best \& Tyler, 2011b) found that newly immersed learners with larger L2 vocabularies did not improve their L2 speech perception after 6-8 months of additional L2 immersion. The researchers predicted that, though early L 2 vocabulary expansion facilitates improvements in L2 segmental perception, a larger L2 vocabulary may constrain further L2 speech perception, as the larger vocabulary allows the learner to function adequately in the L2. Bundgaard-Nielsen, Best, Kroos, and Tyler (2012) further tested the association between L2 size and L2 speech learning in a study on L2 vowel intelligibility of adult Japanese learners of Australian English, who differed only in the size of their L2 vocabularies. They found that newly immersed L2 learners with larger L2 vocabularies produce more intelligible L2 vowels than newly immersed L2 learners with smaller L2 vocabularies, thus indicating a close association between L2 vocabulary development and L2 segmental production accuracy. Other studies have also found L2 vocabulary size to be the significant factor in the perception and production performance of L2 speakers (Cerviño \& Mora, 2009; Doty, Rogers \& Bryant, 2009), which indicates that the lexicon, rather than overall L2 proficiency, is related to L2 phonological development.

\subsection{Second language speech perception: Prelexical and lexical- phonological categorization}

Two of the existing models of second language speech, the Speech Learning Model (SLM, Flege, 1995), and the Perceptual Assimilation Model (PAM \& PAM-L2, Best, 1995; Best \& Tyler, 2007), propose that adult L2 speakers' successful phonological acquisition depends on their perceptual ability to perceive phonemic and phonetic (dis)similarities between the phonemes of the L1 and the target language (i.e., the perceptual correspondence between L1 and L2 phonemic categories). The SLM predicts that a new L2 category is difficult to establish if the degree of perceived phonetic difference between the L2 sound and its closest L1 category is small. In this scenario, the L2 sound will be assimilated to an L1 phoneme, leading to a single merged L1-L2 category. Conversely, if the perceived phonetic dissimilarity between an L2 sound and its closest L1 category is large enough, a new category will be formed for the L2 sound. The perceived relationship between L1 and L2 sounds may, however, change given sufficient L2 experience. Three processes that are essential to learn a new L2 sound underlie the SLM, viz., the mapping of the acoustic input onto a prelexical segmental unit (prelexical phonological categorization), the access to its corresponding lexical form (phono-lexical categorization), and the storing of that category in long-term memory (phono-lexical representation) to be retrieved in speech comprehension (lexical encoding) and production (lexical decoding) (Eisner \& McQueen, 2018). The main proposition of the PAM-L2 is in line with that of the 
SLM in that it proposes that L2 phonological categorization is determined by cross-linguistic influence (CLI), specifically that discrimination of an L2 contrast can be predicted based on how each member of the contrast is assimilated to L1 categories. However, unlike the SLM, this model rejects the assumption that categories are stored as mental representations, arguing instead that L2 perception involves the assimilation of articulatory gestures. Although the PAM-L2 suggests that (prelexical) phonological categorization may not correspond to accurate phono-lexical representation, this is not further discussed. However, the possible mismatch between prelexical perceptual categorization and the phono-lexical representation is supported by several studies (Amengual, 2016; Cutler, Weber \& Otake, 2006; Darcy, Daidone \& Kojima, 2013; Solé, 2013; Weber \& Cutler, 2004). Cutler, Weber, and Otake (2006) and Weber and Cutler (2004) reported that L2 learners are successful in contrasting two L2 categories at the lexical level even if showing inaccurate phonological categorization. Solé (2013) found that L2 contrasts that are not easily distinguishable in pseudo words can be differentiated in real words. The researcher interpreted this finding as an indication that L2 phonological categories may be formed after lexical categories, which are learned as a whole. Conversely, other studies have shown that L2 lexical representation may not be target-like despite accurate phonological categorization (Amengual, 2016; Darcy, Daidone \& Kojima, 2013).

Therefore, in order to further test the perception of L2 vowels and, in particular, the L2 learners' ability to categorize acoustic input (prelexical phonological categorization) and the mapping to its corresponding lexical form (phono-lexical categorization), in the current study, the two categorization processes involved in L2 vowel perception will be tested in two identification tasks, one with pseudo words and the other with real words.

\subsection{Second language speech perception of English vowels by Portuguese learners}

In previous studies on L2 acquisition of English vowels by native European Portuguese speakers, difficulties in both perception and production of the English vowel contrasts $/ \mathrm{i}-/ \mathrm{I} /, / \varepsilon /-/ æ /$ and $/ \mathrm{v} /-\mathrm{u} /$ were found (Bion, Escudero, Rauber \& Baptista, 2006; Nobre-Oliveira, 2007; Rato et al., 2014 Rato, 2014; Rato \& Rauber, 2015; Rauber, 2010). The findings suggested that the English phonological categories /I/, /æ/ and / / / tend to be assimilated to the Portuguese vowel sounds $/ \mathrm{i} /, / \varepsilon /$ and $/ \mathrm{u} /$, respectively, and no distinction between the two vowels of each pair was made due to their acoustic and articulatory proximity and high degree of perceived cross-linguistic (L1-L2) phonetic similarity, leading to the merging of two distinct L2 English vowel categories into one L1 category. These findings showed that proficient learners of English had not yet been able to establish phonemic categories for non-native vowels that differ acoustically in terms of spectral quality and duration from corresponding vowels in the L1 but are perceptually similar to native sounds. To understand the difficulty in 
the perception of these L2 English vowel contrasts, Rato (2018) measured the degree of cross-language (dis)similarity between the English and the European Portuguese vowels with a perceptual assimilation task in which L2 English vowels were mapped onto native vowel categories and rated for goodness-of-fit to L1 vowels. The results confirmed that the identical $\mathrm{L} 2$ vowels $/ \mathrm{i} /, / \varepsilon /$, and $/ \mathrm{u} /$ were consistently mapped to the corresponding Portuguese vowels $/ \mathrm{i} /$ and $/ \mathrm{u} /$ and $/ \varepsilon /$, but the similar vowels $/ \mathrm{I} /$ and $/ \mho /$ were categorized as poor exemplars of both Portuguese /i/ and /e/, and /o/ and / $\mathrm{u} /$, thus creating bi-directional asymmetries in the perception of the target vowels, and L2 vowel /æ/ was assimilated to L1 /a/. These studies examined phonological representation of L2 vowels embedded in real words. To further explore L2 English vowel perception, this study investigates prelexical phonological vowel categorization by examining the effect of stimulus type - real words and pseudo words - on vowel identification.

\section{The European Portuguese and the southern British English vowel systems}

The European Portuguese (EP) vowel system is comprised of eight stressed oral phonemes $(/ \mathrm{i} /, / \mathrm{e} /, / \varepsilon /, / \mathrm{r} /, / \mathrm{a} /, / \mathrm{o} /, / \mathrm{o} /, / \mathrm{u} /)$, one unstressed vowel $([\mathrm{i}])$, and five nasal vowels $(\tilde{\mathrm{i}} /, / \tilde{\mathrm{e}} /, / \tilde{\mathrm{e}} /, / \tilde{\mathrm{o}} /, / \tilde{\mathrm{u}} /)$. In pretonic position, all oral vowels occur, but, in posttonic position, the inventory is reduced to four ([i], [i], [e] , [u]), and in word-final position to three $([\mathrm{i}],[\mathrm{k}],[\mathrm{u}])$. The five nasal vowels occur in pretonic

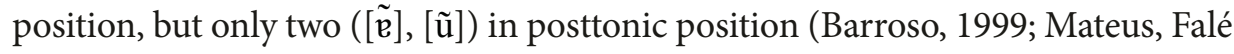
\& Freitas, 2005). The EP vowels contrast in spectral quality and intrinsic duration, with lower vowels being longer than higher vowels (Escudero et al., 2009).

The southern British English (SBE) vowel inventory includes 11 stressed vowels /i: I $\varepsilon$ 3: $\mathfrak{x}$ a: $\mathfrak{p}$ o: $\mathrm{u}: \mho /$, one unstressed vowel ([ə]), five falling diphthongs /e ә ə Spectral differences are the primary cue that differentiates tense (/i: $3:$ a: $0: \mathrm{u}: /$ ) and lax $(/ \mathrm{I} \varepsilon æ \Lambda \mathrm{D} v /)$ vowel sounds and duration is a secondary cue in some varieties (See Figures $1 \& 2$ for the vowel inventories).

Figure 1. EP vowel inventory

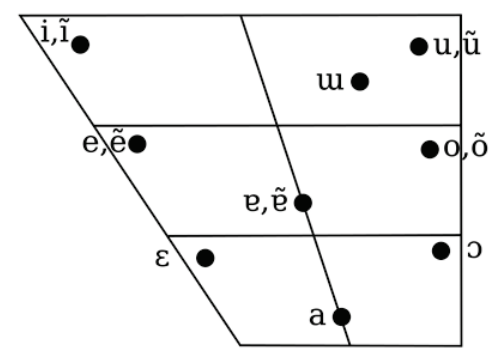

(Adapted from Cruz-Ferreira,1995)
Figure 2. SBE vowel inventory

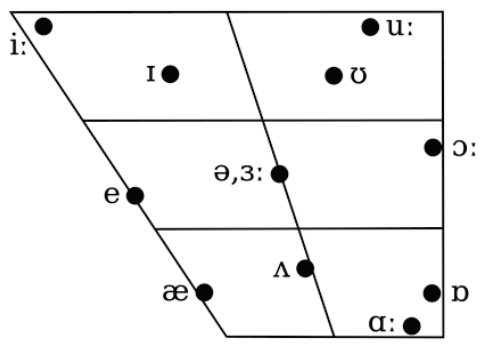

(Adapted from Roach, 2004) 
The target sounds investigated in the present study include six SBE vowels: /i: I $\varepsilon æ 3: \Lambda /$. The decision to investigate the perception of this vowel subset was motivated by previous research on the acquisition of L2 English sounds by native adult speakers of European Portuguese. The findings include discrimination failure of vowel contrasts $/ æ /-/ \varepsilon /, / \varepsilon /-/ \mathrm{I} /$, / $\mathrm{u}: /-/ \mho /$, and $/ \mathrm{N} / \mathrm{-} / \mathrm{a} /$ (Flege, 1994, as cited in Flege, 1995) and difficulties in the identification and production of the vowel contrasts $/ \mathrm{i} / /-\mathrm{I} /, / \mathfrak{\text { }} /-/ \varepsilon /$ and /u:/-/v/ (Rato, 2014; Rato et al., 2014; Rato \& Rauber, 2015); however, no results have been reported for the lax-tense central vowel pair $/ \Lambda /-/ 3: /$. The choice of SBE as the target English variety was determined by the fact that it is the one taught in the undergraduate English program in which the participants were enrolled.

\subsection{Research questions and hypotheses}

The present research investigates the perception of L2 English vowels in real and pseudo words by adult European Portuguese learners to answer the following research questions:

RQ1: Which L2 English vowels are more difficult to categorize for Portuguese learners?

Following previous research, we hypothesized that participants would have more difficulty with vowels $/ \mathrm{I} /$ and $/ \mathfrak{x} /$ which tend to be assimilated to Portuguese vowels /i/ and /a/ due to their high degree of perceived cross-linguistic phonetic similarity. Identical English vowels /i/ and / $/ \varepsilon /$ were expected to be more easily perceived. Although no previous findings have been reported for the vowel pair $/ 3: /-/ \Lambda /$, more difficulty would be expected for the lax counterpart, which has a shorter duration.

RQ2: Does stimulus type (real vs. pseudo words) have an effect in L2 vowel perception?

Given previous findings that indicate proficient learners of Portuguese have difficulty in the establishment of L2 phonemic vowel categories that are perceptually similar to L1 phonemes, we predicted that lexical-phonological categorization of the target vowels would be more accurate than prelexical phonological categorization, i.e., L2 learners would more successfully identify English vowels embedded in real words than in pseudo words. We also predicted that the L2 learners, who had a large vocabulary size and a proficient English level, would perceive the contrast of two categories at the lexical level, despite inaccurate prelexical phonological categorization, i.e., even if they had not yet established the target vowel categories.

RQ3: Which learner variables predict the perceptual performance of Portuguese learners in English vowel identification? 
Although the participant poll was recruited from the same proficiency-level English course, individual variation would be expected to emerge given the different L2 experience of learners in terms of age of onset of learning, length of formal instruction, amount of L2 use, and vocabulary size. We hypothesized that all factors would account, to different degrees, for the variance in perceptually categorizing L2 speech sounds, but age of learning and L2 use would be the most significant predictors.

\section{Method}

\subsection{Participants}

A total of twenty-nine adult Portuguese learners of L2 English between 18 and 22 years of age (Mean: 19.2 yrs., $S D=1.2$ ) were recruited to participate in this study. All participants were first-year English majors at a Portuguese university enrolled in weekly four-hour English language courses in the second academic semester. Students received course credit for their voluntary participation.

All participants ( $16 \mathrm{~F}$ and $13 \mathrm{M}$ ) had started learning English in a formal classroom setting in Portugal between 6 and 11 years old, for an average duration of approximately 11 years (Mean=10.8 years, $\mathrm{SD}=1.4$; range: $6-11$ ) at the time of testing. The group reported using English on average 30.5\% ( $\mathrm{SD}=13.6)$ of the time, but showed some variation in their self-reported daily language use, which ranged from $10 \%$ to $60 \%$, mostly in interactions with other non-native speakers of the target language. None of the participants reported having spent longer than three months in an English-speaking country or reported having any hearing impairment.

Although all participants were enrolled in a B1+-level English course, they self-rated their English proficiency according to the CERF levels (Common European Framework of Reference for Languages), and 58.6\% reported having a B2 level (Independent User), 24.1\% a C1 level, and 6.9\% a C2 level (Proficient Users). Vocabulary size was also used as a measure of the learners' overall language proficiency (Mean=6007; SD=1273; range: 2650-8050), which indicated that $48.1 \%$ of the participants had a C1 level, $24.1 \%$ a B2 level, $13.8 \%$ a B1 level, $6.9 \%$ a C2 level, and $6.9 \%$ an $\mathrm{A} 2$ level. Both measures show that despite the intra-group variability, most learners had an upper intermediate or advanced proficiency level in English. Eighteen participants reported having a beginner (A1-A2) level of Spanish and eight students a beginner level of French; however, none of the learners included any of these languages in their self-reported daily use of languages, which indicated that they do not frequently use these other languages.

\subsection{Vowel Identification Task}

The participants' perception of the target vowels was tested with two sevenalternative forced-choice (7AFC) identification tasks, in which a single auditory 
stimulus (CVC words) was presented and the listener was required to assign a label to the vowel heard from the seven possible responses provided. The response options included phonetic-like ${ }^{1}$ symbols and two examples of real words for each vowel since the correspondence grapheme-phoneme in English is somewhat opaque. The response options were the following: /ae/ ash, mass; /^/ sun, thus, /I/ fish, his; /i:/ cheese, leaf; /3:/ earth, first; /e/ less, west; /a:/ arm, palm. The order of administration of the identification tasks - one with real words and the other with pseudo words - was counterbalanced across participants, and in both the order of stimuli presentation was randomized. No trial-by-trial feedback was provided throughout the test, but learners had access to the total global number of correct and incorrect responses at the end of the session. Reaction times (RTs) between the offset of the stimulus and response, provided by the click of the mouse, were also measured by the software. The stimuli of the perception tasks included both real and pseudo CVC words produced naturally by a female speaker and a male speaker of standard southern British English (SBE) (see Carlet, 2017, for a description of stimuli elicitation, preparation, and validation by native speakers).

Eighteen CVC pseudo words ( 6 target vowels $\mathrm{x} 3$ words $\mathrm{x} 2$ talkers), repeated twice, and 12 CVC real words (6 target vowels $\mathrm{x} 2$ words $\mathrm{x} 2$ talkers), repeated three times, were presented in the tests, totaling 144 trials. In addition, 2 real words and 2 pseudo words with non-target vowel /a:/ (1 vowel $\mathrm{x} 4$ words $\mathrm{x}$ 2 talkers), repeated twice, were included as fillers in a total of 16 trials. Eight practice trials were also included for familiarization with the tasks. The CVC stimuli included the target vowels flanked by stops and fricatives (see Appendix A for list of stimuli).

\subsection{Procedure}

Participants were tested in a quiet computer room of the university in three joint sessions. The tests were run with TP software 3.1 (Rauber, Rato, Kluge \& Santos, 2012) on several computers simultaneously. Each participant completed the tests individually and heard the audio stimuli over NGS MSX6 Pro stereo headphones. Before the test started, participants read the instructions shown on the computer screen followed by an eight-trial practice with stimuli not included in the experiment. The two tests lasted approximately 15-20 minutes, but participants could take a short break at any time during the session. After the administration of the identification tasks, participants completed two vocabulary size tests: X-Lex and Y-Lex (Meara \& Miralpeix, 2006). Both estimate how many words the participants know (the meaning). The X-Lex tests the knowledge of the 5.000 most frequent words in English, and the Y-Lex measures the knowledge of the 10.000 most frequent words, which requires a more advanced vocabulary knowledge. The participants were individually presented with words one at a time on a computer screen and indicated whether they knew the meaning of each word in a yes-no format response. Each test presented items from five different frequency bands. The X-Lex was run first followed by the Y-Lex test. The self- 
paced tests were administered on a computer and each took around 5 minutes to complete. L2 vocabulary size score was obtained by adding the corrected ${ }^{2}$ $\mathrm{X}$-Lex score to the corrected Y-Lex score, so that the possible range of scores was 0-10.000 words (Meara, 2005).

Before the end of the session, participants also completed a questionnaire, which included 10 questions regarding demographic data and information about their language background, such as age of learning of the target language, years of formal instruction, level of proficiency, daily L1 and L2 use, and knowledge of other languages.

\section{Results}

Participants' responses in the vowel identification tests were analyzed and the percentage of accurate responses for each condition (vowel/stimulus type) was computed. Descriptive statistics are presented in Table 1.

Table 1. Vowel identification accuracy (\%).

\begin{tabular}{lll}
\hline vowel & \multicolumn{2}{l}{ stimulus type } \\
\hline & real words & pseudo words \\
\cline { 2 - 3 } /i:/ & $81.0(22.3)$ & $65.0(22.2)$ \\
/I/ & $71.1(29.1)$ & $64.8(20.1)$ \\
$/ \varepsilon /$ & $89.2(20.2)$ & $76.0(18.7)$ \\
/æ/ & $44.4(36.2)$ & $36.9(26.5)$ \\
/3:/ & $83.6(20.1)$ & $41.3(22.9)$ \\
$/ \Lambda /$ & $75.0(30.8)$ & $39.6(26.9)$ \\
\hline
\end{tabular}

Standard deviations in brackets.

In the identification of vowels in real words, the ranking of accurate responses, from the most to the least accurate, was the following: $/ \varepsilon />/ 3: />/ \mathrm{i}: />|\Lambda />/ \mathrm{I} />| æ /$. The participants performed more accurately in the identification of vowels $/ \varepsilon /$, /3:/ and /i:/, with accuracy rates between 81 and $89 \%$, and more poorly, below chance level (44\%), in the categorization of vowel /æ/. Vowels $/ \mathrm{A} /$ and $/ \mathrm{I} /$ were correctly identified between $75 \%$ and $71 \%$ of the times.

With lower results ranging from 40 to $76 \%$, the ranking of correct vowel identifications in pseudo words was $/ \varepsilon />/ \mathrm{i}:>/ \mathrm{I} />/ 3: />/ \Lambda />/ \mathfrak{x} /$, from the most to the least accurate. The participants identified vowels $/ \varepsilon /$, /i:/ and $/ \mathrm{I} />$ more correctly, and vowels $/ 3: /, / \Lambda /$, and $/ \mathfrak{x} /$ more poorly, below chance level.

To further understand the patterns of perceptual inaccuracy, the correct and incorrect identifications were tabulated in confusion matrices for each perceptual test (Tables $2 \& 3$ ). Rows in the matrices correspond to the vowels that were heard and columns to the vowel categories to which listeners mapped the sounds heard. 
Table 2. Confusion matrix of the identification test with real words.

\begin{tabular}{|c|c|c|c|c|c|c|c|}
\hline \multirow{2}{*}{$\begin{array}{l}\text { stimulus } \\
\text { heard }\end{array}$} & \multicolumn{7}{|c|}{ identified vowel } \\
\hline & /i:/ & $/ \mathbf{I} /$ & $|\varepsilon|$ & $/ \mathfrak{e} /$ & $/ 3: /$ & $/ \mathbf{A} /$ & $/ \mathbf{a}: /$ \\
\hline /i:/ & $\begin{array}{l}\mathbf{8 1} \\
(22.3)\end{array}$ & $\begin{array}{l}17.7 \\
(22.8)\end{array}$ & $\begin{array}{l}1.3 \\
(5.1)\end{array}$ & & & & \\
\hline$/ \mathbf{I} /$ & $\begin{array}{l}22.8 \\
(29.7)\end{array}$ & $\begin{array}{l}71.1 \\
(29.1)\end{array}$ & $\begin{array}{l}5.2 \\
(12.3)\end{array}$ & & $\begin{array}{l}0.9 \\
(3.2)\end{array}$ & & \\
\hline $\mid \varepsilon /$ & & & $\begin{array}{l}\mathbf{8 9 . 2} \\
(20.3)\end{array}$ & $\begin{array}{l}8.6 \\
(18.9)\end{array}$ & $\begin{array}{l}2.2 \\
(9.5)\end{array}$ & & \\
\hline$/ \mathfrak{a} /$ & & & $\begin{array}{l}7.3 \\
(15.5)\end{array}$ & $\begin{array}{l}\mathbf{4 4 . 4} \\
(36.2)\end{array}$ & $\begin{array}{l}2.2 \\
(4.8)\end{array}$ & $\begin{array}{l}4.3 \\
(11.2)\end{array}$ & $\begin{array}{l}41.8 \\
(33.9)\end{array}$ \\
\hline /3:/ & & & & $\begin{array}{l}3.9 \\
(13)\end{array}$ & $\begin{array}{l}\mathbf{8 3 . 6} \\
(20.1)\end{array}$ & $\begin{array}{l}11.6 \\
(17)\end{array}$ & $\begin{array}{l}0.9 \\
(4.6)\end{array}$ \\
\hline $\mid \mathbf{s} /$ & & & $\begin{array}{l}1.7 \\
(9.3)\end{array}$ & $\begin{array}{l}1.7 \\
(5.5)\end{array}$ & $\begin{array}{l}15.1 \\
(21.5)\end{array}$ & $\begin{array}{l}75 \\
(30.8)\end{array}$ & $\begin{array}{l}6.5 \\
(21.3)\end{array}$ \\
\hline
\end{tabular}

Mean percent identification (\%) and standard deviations in brackets. Boldfaced values indicate the modal categorization response.

The confusion matrix (Table 2) indicates that, in the identification test with real words, four vowels were consistently misidentified with their counterparts. The lax front high vowel /I/ was confused with its tense counterpart /i:/, and vice versa, and $/ \Lambda$ / was inaccurately mapped onto /3:/, and vice versa. The contrast $/ \varepsilon$ $æ /$ shows a different pattern. Vowel $/ \varepsilon /$ was sporadically categorized incorrectly as its closest competitor /æ/, but the latter vowel was mostly confused with the back low vowel /a:/ being used as a distractor vowel in the task.

Table 3. Confusion matrix of the identification test with pseudo words.

\begin{tabular}{|c|c|c|c|c|c|c|c|}
\hline \multirow{2}{*}{$\begin{array}{l}\text { Stimulus } \\
\text { heard }\end{array}$} & \multicolumn{7}{|c|}{ identified vowel } \\
\hline & $/ \mathbf{i}: /$ & $/ \mathbf{I} /$ & $/ \varepsilon /$ & $/ \mathbf{a} /$ & /3:/ & $\mid \mathbf{A} /$ & $/ \mathbf{a}: /$ \\
\hline /i:/ & $\begin{array}{l}\mathbf{6 5} \\
(22.3)\end{array}$ & $\begin{array}{l}34.6 \\
(22.5)\end{array}$ & $\begin{array}{l}0.3 \\
(1)\end{array}$ & & $\begin{array}{l}0.1 \\
(0.7)\end{array}$ & & \\
\hline$/ \mathbf{I} /$ & $\begin{array}{l}27.3 \\
(17.4)\end{array}$ & $\begin{array}{l}\mathbf{6 4 . 8} \\
(20.2)\end{array}$ & $\begin{array}{l}5.8 \\
(7.3)\end{array}$ & & $\begin{array}{l}2.1 \\
(3.7)\end{array}$ & & \\
\hline $\mid \boldsymbol{\varepsilon} /$ & & $\begin{array}{l}0.8 \\
(4.6)\end{array}$ & $\begin{array}{l}76.3 \\
(18.7)\end{array}$ & $\begin{array}{l}14.9 \\
(15)\end{array}$ & $\begin{array}{l}2.6 \\
(8.4)\end{array}$ & & $\begin{array}{l}5.4 \\
(9.4)\end{array}$ \\
\hline$/ \mathfrak{a} /$ & & & $\begin{array}{l}3.1 \\
(6.7)\end{array}$ & $\begin{array}{l}37 \\
(26.5)\end{array}$ & $\begin{array}{l}4.8 \\
(6.9)\end{array}$ & $\begin{array}{l}5.6 \\
(7)\end{array}$ & $\begin{array}{l}49.5 \\
(30)\end{array}$ \\
\hline /3:/ & & & $\begin{array}{l}2.5 \\
(4.5)\end{array}$ & $\begin{array}{l}6.1 \\
(11.9)\end{array}$ & $\begin{array}{l}41.3 \\
(22.9)\end{array}$ & $\begin{array}{l}42.7 \\
(24.9)\end{array}$ & $\begin{array}{l}7.4 \\
(11)\end{array}$ \\
\hline$/ \mathbf{A} /$ & & & $\begin{array}{l}0.1 \\
(0.4)\end{array}$ & $\begin{array}{l}15.3 \\
(18.2)\end{array}$ & $\begin{array}{l}24.6 \\
(21.8)\end{array}$ & $\begin{array}{l}39.6 \\
(26.9)\end{array}$ & $\begin{array}{l}20.4 \\
(17.5)\end{array}$ \\
\hline
\end{tabular}

Mean percent identification (\%) and standard deviations in brackets. Boldfaced values indicate the modal categorization response.

In the identification task with pseudo words, despite the lower accuracy scores, the same confusion patterns were apparent (Table 3). The high front 
vowels and the mid central vowels were interchangeably misidentified as their counterparts. The lax vowel/I/ was incorrectly categorized as its tense counterpart $/ \mathrm{i}: /$, and vice versa, and lax $/ \Lambda /$ was frequently confused with its tense vowel competitor $/ 3: /$, and vice versa. In the case of the front contrast $/ \varepsilon-æ /$, vowel $/ \varepsilon /$ was seldom categorized as its counterpart /æ/, but /æ/ was more predominantly mapped onto vowel /a:/.

To further explore whether there was a relationship between the identification of the target vowels in both tasks, Pearson Correlation tests were run. Positive significant correlations were found in the identification of vowels /i:/ $(r=.43$, $p=.02), \mathrm{I} /(r=.75, p>.001), / \mathfrak{l} /(r=.74, p>.001)$ and $/ \Lambda /(r=.42, p=.03)$ which indicates that L2 learners' perceptual performance was associated in both tasks, in which better or poorer identification in the identification test with real words was related to the identification scores in pseudo words. This suggests that although learners had lower scores in identifying the target vowels in pseudo-words than in real words, their overall performance in the identification of four of the target vowels was consistent across tasks.

To test whether phono-lexical perception was more or less accurate than phonological categorization of the target vowels, a comparison of the participants' identification performance in real words and pseudo words was conducted. $T$ tests for paired samples were run which yielded significant differences in the categorization of four of the target vowels, namely /i:/ $(t=3.64$ (28), $p=.001), / \varepsilon /(t=2.97$ (28), $p=.006)$, /3:/ ( $t=6.59$ (28), $p>.001)$, and $/ \Lambda /(t=6.08$ (28), $p>.001)$. Although participants' identification accuracy was generally higher in the identification of the target vowels in real words than in pseudo words, the categorization of English vowels /i:/, / $/ /, / 3: /$ and $/ \Lambda /$ was significantly better when learners heard those vowels presented in lexical units. In the case of the central vowels $/ 3: /$ and $/ \Lambda /$, the accurate mapping of L2 vowel phones was significantly lower, with participants performing below chance level when they heard them in pseudo words.

Figure 3. Identification accuracy in real and pseudo words.

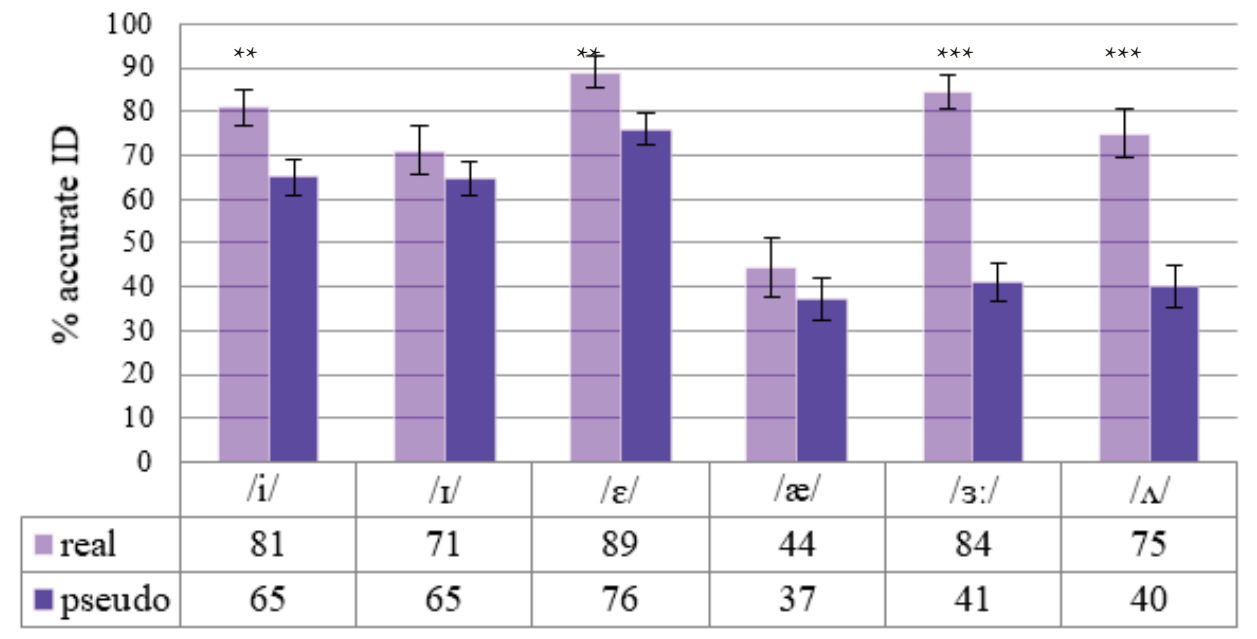

Error bars represent \pm 1 standard error. Significance levels: ${ }^{*}<.05 ;^{* *}<.01 ;^{* *}<.001$ 
The overall average identification of the six target vowels was calculated to assess which individual factors predicted the participants' perceptual performance in the two identification tasks. A multiple linear regression analysis was performed to investigate the degree to which age of learning (AOL), length of formal instruction (LFI), L2 English use and vocabulary size predict participants' identification/perceptual performance. A multiple linear regression was calculated to predict participants' identification/perceptual performance based on their AOL, LFI, language use and vocabulary size.

Using the stepwise method, a significant model emerged, $F(1,27)=6.898$, $p=.014)$, for daily use of $L 2$ English ( $\beta=0.45$ ), with a $R^{2}$ of .174 . The other predictors, AOL, LFI, and vocabulary size, were excluded from the model. The results revealed that only L2 English use explained variance in vowel identification.

The results of further correlation analysis showed that the amount of daily use of English was positively associated with the identification vowels $/ \mathrm{I} /$ in both real $(r=.40, p=.03)$ and pseudo words $(r=.49, p=.007)$ and, $/ \varepsilon /(r=.46, p=.012)$ and

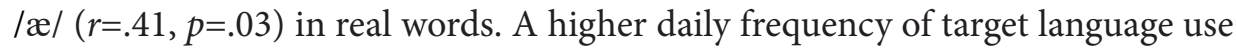
was related with a more accurate identification of the target vowels.

\section{Discussion \& Conclusions}

The present study investigated the role of stimulus type on L2 English vowel perception and explored the effect of learner factors, viz. age of learning, length of formal instruction, language use, and vocabulary size, on the learners' ability to categorize L2 vowel sounds. Portuguese L2 learners were tested on six English vowels (/i: г $\varepsilon$ æ $3: \Lambda /$ ) with two 7AFC identification tasks, comprising real-word and pseudo-word stimuli. The learner data were collected with two vocabulary size tests and a language background questionnaire.

The predicted challenges in the perception of the target English vowels were determined by previous research with L2 European Portuguese speakers, conducted by Rato and colleagues (e.g., Kivistö-de Sousa, Carlet, Julkowska \& Rato, 2017; Rato, 2018; Rato \& Rauber, 2015; Rato, 2014; Rato et al., 2014). Therefore, we hypothesized that identical vowels $/ \mathrm{i}$ / and $/ \varepsilon /$ would be more easily perceived and similar L2 vowels /I/ and /æ/ would be more challenging. Concerning the vowel pair $/ 3: /-/ \Lambda /$, more difficulty would be expected for the lax counterpart.

The results partially confirmed our predictions. Indeed, L2 /i:/ and / $\varepsilon /$ were the more accurately identified vowels, in both conditions, which suggests that separate phonological and lexical categories have been formed for these sounds. Vowels $/ 3: /$ and $/ \Lambda /$, however, were only correctly categorized when embedded in real words, with below chance-level average identifications in pseudo words, which indicates they have been formed as merged phono-lexical categories in the L2 learners' mind. Vowel /æ/ was the most difficult vowel to categorize with very low accurate scores $(<45 \%)$, regardless of stimulus type. This suggests that a phono-lexical representation for this vowel category may not yet have been stored in the learners' long-term memory. An examination of the perceptual 
confusion patterns revealed that the lax vowel /I/ was incorrectly categorized as its tense counterpart $/ \mathrm{i}$ //, and vice versa, and vowel $/ \Lambda /$ was often confused with its corresponding tense vowel /3:/, and vice versa. In the case of the front contrast $/ \varepsilon$ $æ /$, when incorrectly identified, vowel /ع/ was mapped onto its counterpart /æ/, but /æ/ was more frequently categorized as vowel /a:/. The possible explanations for the misperception of vowel /æ/ as /a:/ is, on one hand, their articulatory and acoustic similarity in terms of tongue height (F2 formant), both being open vowels. Although vowel /a:/ was included as a distractor vowel, we examined its identification scores and error patterns, and found that in both conditions it was poorly categorized (53\% in real words, and $30 \%$ in pseudo words), being often misidentified as vowel /æ/ ( $15 \%$ in real words, and $61 \%$ in pseudo words). On the other hand, they are both acoustically and articulatorily similar to L1 Portuguese vowel /a/. Rato (2018) reported the results of an L2-to-L1 perceptual assimilation task that revealed /æ/ was considered a fair exemplar of Portuguese vowel category /a/; however, no results were reported for /a:/. The researcher predicted that this perceived cross-linguistic phonetic similarity would thus impede the establishment of a new L2 category for /æ/. These additional results suggest that bi-directional asymmetries in the perception of the vowel pair /æ/-/ $\mathrm{a}$ / may have hindered the formation of phono-lexical representations for both vowels. Another factor that may have had an effect on the creation of separate target-like categories was orthography. Although orthographic information may help L2 learners resolve perceptual confusability in the lexicon, in some cases it may also have an interfering effect on L2 phono-lexical representations. In the specific case of this vowel pair, there is no one-to-one grapheme-phoneme correspondence with both vowels being represented by the same grapheme $<$ a $>$. Research has shown that orthography has an impact not only in phono-lexical categorization (Moyer, 2013), but also in prelexical phonological categorization (Escudero \& Wanrooij, 2010).

Considering both previous research that reported proficient Portuguese learners' difficulty in categorizing and producing the English vowel contrasts / $\mathrm{i}: /-/ \mathrm{I} /, \mid \mathfrak{x} /-/ \varepsilon /$ and $/ \mathrm{u}: / / \mathrm{v} /$, which suggests these L2 vowel categories may not have been established, and studies that reported a faster and more accurate mapping of L2 sounds in real words than in non-word stimuli (Solé, 2013; Cutler, Weber \& Otake, 2006; Weber \& Cutler, 2004), we hypothesized that Portuguese learners would identify the target vowels more accurately when presented in words they recognized than in pseudo words. The results provided evidence that lexical-phonological categorization of the target vowels was more accurate than prelexical phonological categorization, that is, vowel identification was overall facilitated when the vowel sounds were presented in real words, which is in line with previous findings (e.g., Solé, 2013). In particular, vowels /i:/, / / /, /3:/ and / / / were significantly more easily identified in real words than pseudo words, thus confirming our hypothesis. This finding can be interpreted as an indication that lexical categories, which are learned as a whole, may have been established before phonological categories, and therefore, separate L2 phonological categories for 
these English vowels have not yet been fully established. This result also suggests that, although the target vowel contrasts are somewhat preserved (i.e., are not fully merged) in the L2 learners' lexicon, the sound categories may only be abstracted from lexical items at a later stage of L2 learning.

Finally, we predicted that all subject factors would account for the learners' ability to categorize L2 vowels, to varying degrees, with age of learning and L2 use expected to be the most significant predictors. However, the results from regression analysis only showed a significant linear relationship between L2 use and L2 vowel identification, with amount of daily L2 use significantly accounting for $17.4 \%$ of the variance in vowel identification accuracy. This finding showed that greater L2 use enhanced learners' perceptual abilities, thus suggesting that L2 vowel acquisition is dependent on language use patterns (Jia et al., 2006; Piske et al., 2001). The number of years L2 learners studied English and the age at which they started learning English did not correlate with perception performance. Although the participants were recruited from the same learning context, viz. first-year English language courses in a Portuguese university, we predicted that interlearner variation would be found concerning their language background and vocabulary size as widely attested in research with L2 learners. However, a closer examination of the participants' data, and particularly the standard deviation measures, revealed that there was little intragroup variation in terms of age of learning (Mean=7.7 years, $\mathrm{SD}=1.3$ ) and length of formal instruction (Mean=10.8, SD=1.4). The average frequency of self-reported daily use of L2 English was 30.5\%, but the standard deviation was $13.6 \%$ in a range of 10 $60 \%$, which indicates that it was the variable in which L2 learners differed the most. In sum, since the group of L2 was relatively homogeneous regarding their English language proficiency and experience, except for amount of L2 use, our hypothesis was partially rejected. To better examine the role of these learner variables on L2 vowel perception, the analysis of a more heterogeneous group of learners differing in age of learning and length of formal instruction should be conducted in future studies. The explanation for the lack of an association between the learners' L2 vocabulary size and L2 vowel identification accuracy might be explained to some extent by the slight variation found in the L2 learners' vocabulary size (Mean $=6007, \mathrm{SD}=1273$, in a possible range from 0 to 10.000 words), but to a greater extent by the fact that this group of learners, who started studying English at an approximate age of 8 years, and had been exposed to 11 years of formal instruction, may have reached a "perceptual reattunement and rephonologization ${ }^{3}$ plateau" (Bundgaard-Nielsen, Best, \& Tyler, 2011a), at some point in their L2 vocabulary development, more specifically, once they acquired enough vocabulary that allowed them to function adequately in the L2. Though the findings by Bundgaard-Nielsen and her colleagues provided evidence that early L2 vocabulary expansion facilitates improvement in L2 segmental perception and production, they also found that a larger L2 vocabulary size may limit further L2 vowel categorization and production. In the case of the learners of the present study, who are in a later phase of vocabulary acquisition and who had a relatively 
large L2 vocabulary size ( $>6.000$ words), an association between L2 vocabulary size and the ability to perceive L2 vowel sounds was thus not found.

In sum, the present study provided further empirical data to the research on L2 perception of English vowels by native European Portuguese speakers. The findings indicate that, within a group of learners with a similar language background, there are different stages in the development of new L2 categories, which is influenced not only by linguistic factors such as cross-linguistic influence (viz. degree of perceived L2-L1 (dis)similarity), orthography and lexical status of the stimuli, but also by learners' variables such as language use. Research on L2 learners' perception ability should then integrate the analysis of both linguistic factors and individual differences for a better understanding of the development of L2 speech. We conclude by highlighting the importance for L2 speech learning of not only providing learning environments in which learners are encouraged to use the L2 as much as possible, but also of integrating systematic and focused segmental training (in real and pseudo words) of L2 English vowels.

Notes

1. TP (version 3.1) software does not recognize IPA phonetic symbols.

2. The 'corrected score' adjust the raw scores to account for the false-alarm answers.

3. The establishment of an L2 phonological system, by modification or addition to the L1 phonological system.

\section{References}

Aliaga-Garcia, C. (2017). The effect of auditory and articulatory phonetic training on the perception and production of L2 vowels by Catalan-Spanish learners of English [Unpublished Doctoral dissertation]. University of Barcelona, Spain.

Aliaga-Garcia, C. (2010). Measuring perceptual cue weighting after training: A comparison of auditory vs. articulatory training methods. In K. DziubalskaKołaczyk, M. Wrembel, \& M. Kul (Eds.), New Sounds 2010: Proceedings of the Sixth International Symposium on the Acquisition of Second Language Speech (pp. 2-7). Poznan, Poland.

Amengual, M. (2016). The perception of language-specific phonetic categories does not guarantee accurate phonological representations in the lexicon of early bilinguals. Applied Psycholinguistics, 37(5), 1221-1251.

Barroso, H. (1999). Forma e Substância da Expressão da Língua Portuguesa. Coimbra: Almedina.

Best, C. (1995). A Direct Realist View of Cross-Language Speech Perception. In W. Strange (Ed.), Speech Perception and Linguistic Experience: Issues in Cross Language Research (pp. 171-204). Timonium, MD: York Press.

Best, C., \& Tyler, M. (2007). Nonnative and second-language speech perception: Commonalities and complementarities. In O.-S. Bohn, \& M. Munro (Eds.), Language experience in second language speech learning - In honor of James Emil Flege (pp. 13-34). Amsterdam/Philadelphia: John Benjamins.

Bion, R., Escudero, P., Rauber, A., \& Baptista, B. (2006). Category formation and the role of spectral quality in the perception and production of English front vowels. Interspeech 2006 - ICSLP (pp. 17-21). Pittsburgh, USA. 
Bohn, O-S. (2017). Cross-language and second language speech perception. In E. M. Fernández \& H. S. Cairns (Eds.), Handbook of psycholinguistics (pp. 213-239). West Sussex: Wiley-Blackwell.

Bundgaard-Nielsen, R., Best, C., \& Tyler, M. (2011a). Vocabulary size matters: The assimilation of second-language Australian English vowels to first-language Japanese vowel categories. Applied Psycholinguistics, 32, 51-67.

Bundgaard-Nielsen, R., Best, C., \& Tyler, M. (2011b). Vocabulary is associated with second-language vowel perception performance in adult learners. Studies in Second Language Acquisition, 33, 433-461.

Bundgaard-Nielsen, R., Best, C., Kroos, C., \& Tyler, M. (2012). Second language learners' vocabulary expansion is associated with improved second language vowel intelligibility. Applied Psycholinguistics, 33, 643-664.

Carlet, A. (2017). L2 perception and production of English consonants and vowels by Catalan speakers: The effects of attention and training task in a cross-training study. [Unpublished doctoral dissertation]. Universitat Autònoma de Barcelona, Spain.

Carlet, A. \& Cebrian, J. (2015). Identification vs. discrimination training: Learning effects for trained and untrained sounds. In The Scottish Consortium for ICPhS 2015 (Ed.), Proceedings of the 18th International Congress of Phonetic Sciences. Glasgow, UK: University of Glasgow.

Carlet, A., \& Souza, H-K. (2008). Improving L2 pronunciation inside and outside the classroom: Perception, production and autonomous learning of L2 vowels. Ilha do Desterro, 71(3), 99-123.

Cebrian, J. (2006). Experience and the use of duration in the categorization of L2 vowels. Journal of Phonetics, 34, 372-387.

Cebrian, J., Mora, J. C., \& Aliaga-Garcia, C. (2010). Assessing crosslinguistic similarity by means of rated discrimination and perceptual assimilation tasks. In K. Dziubalska-Kołaczyk, M. Wrembel, \& M. Kul (Eds.), New Sounds 2010: Proceedings of the Sixth International Symposium on the Acquisition of Second Language Speech (pp. 77-82).

Cerviño, E., \& Mora, J.C. (2009). Duration as a phonetic cue in the categorization of /i:, I/, and /s, z/ by Spanish/Catalan learners of English. Journal of the Acoustical Society of America, 125, 2764.

Cruttenden, A. (2014). Gimson's pronunciation of English. Abingdon: Routledge.

Cruz-Ferreira, Madalena. (1995). Illustrations of the IPA: European Portuguese. Journal of the International Phonetic Association, 25, 90-94.

Cutler, A., Weber, A., \& Otake, T. (2006). Asymmetric mapping from phonetic to lexical representations in second-language listening. Journal of Phonetics, 34(2), 269-284.

Darcy, I., Daidone, D., \& Kojima, C. (2013). Asymmetric lexical access and fuzzy lexical representations in second language learners. The Mental Lexicon, 8(3), $372-420$.

Doty, A. Z., Rogers, C. L., \& Bryant, J. B. (2009). Spoken word recognition in quiet and noise by native and non-native listeners: Effect of age of immersion and vocabulary size. Journal of the Acoustical Society of America, 125, 2765.

Eisner, F., \& McQueen, J. M. (2018). Speech perception. In S. Thompson-Schill (Ed.), Stevens' handbook of experimental psychology and cognitive neuroscience (4th ed.). Volume 3: Language \& Thought (pp.1-46). Hoboken: Wiley.

Escudero, P., \& Wanrooij, K. (2010). The effect of L1 orthography on non-native vowel perception. Language and Speech, 53(3), 343-365. 
Escudero, P., Boersma, P., Rauber, A., \& Bion, R. (2009). A cross-dialect acoustic description of vowels: Brazilian and European Portuguese. Journal of the Acoustical Society of America, 126(3), 1379-1393.

Fife-Schaw, C. (2006). Levels of measurement. In G. M. Breakwell, S. Hammond, C. Fife-Schaw, \& J. A. Smith (Eds.), Research methods in psychology (3 ${ }^{\text {rd }}$ ed.) (pp. 5063). London: Sage.

Flege, J. (1995). Second language speech learning: Theory, findings and problems. In W. Strange (Ed.), Speech perception and linguistic experience: Issues in cross language research (pp. 233-277). Timonium, MD: York Press.

Flege, J. E., \& Liu, S. (2001). The effect of experience on adults' acquisition of a second language. Studies in Second Language Acquisition, 23, 527-552.

Flege, J., E. \& Fletcher, K. L. (1992). Talker and listener effects on degree of perceived foreign accent. Journal of the Acoustical Society of America, 91(1), 370-389.

Flege, J. E., Frieda, E. M., Nozawa, T. (1997). Amount of native-language (L1) use affects the pronunciation of an L2. Journal of the Acoustical Society of America, $25,169-186$.

Flege, J. E., Munro, M. J., \& MacKay, I. R. A. (1995a). Effects of age of second language learning on the production of English consonants. Speech Communication, 16, $1-16$.

Flege, J. E., Munro, M. J., \& MacKay, I. R. A. (1995b). Factors affecting strength of perceived foreign accent in a second language. Journal of the Acoustical Society of America, 97, 3125-3134.

Flege, J., \& MacKay, I. (2004) Perceiving vowels in a second language. Studies in Second Language Acquisition, 26, 1-34.

Flege, J., Bohn, O.-S., \& Jang, S. (1997). Effects of experience on non-native speakers' production and perception of English vowels. Journal of Phonetics, 25, 437-470.

Flege, J., MacKay, I., \& Meador, D. (1999). Italian speakers' perception and production of English vowels. Journal of the Acoustical Society of America, 106(5), 2973-4.

Jia, G., Strange, W., Collado, J., \& Guan, Q. (2006). Perception and production of English vowels by Mandarin speakers: Age-related differences vary with amount of L2 exposure. Journal of the Acoustical Society of America, 119(2), 1118-1130.

Kissling, E. M. (2014). What predicts the effectiveness of foreign-language pronunciation instruction? Investigating the role of perception and other individual differences. Canadian Modern Language Review, 70(4), 532-558.

Kivistö-de Sousa, H., Carlet, A., Julkowska, I., \& Rato, A. (2017). Vowel inventory size matters: Assessing cue-weighting in L2 vowel perception. Ilha do Desterro, 70(3), 33-46.

Lord, G. (2005). (How) can we teach foreign language pronunciation? On the effects of a Spanish phonetics course. Hispania, 88(3), 557-567.

Mateus, M. H. M., Falé, I., \& Freitas, M. J. (2005). Fonética e fonologia do português. Lisboa: Universidade Aberta.

Meara, P. M. (2005). Designing vocabulary tests for English, Spanish and other languages. In C. Butler, M. A. Gómez González, \& S. Doval Suárez (Eds.), The dynamics of language use: Functional and contrastive perspectives (pp. 271-285). Amsterdam: John Benjamins.

Meara, P. M., \& Miralpeix, I. (2006). X_Lex: The Swansea advanced vocabulary levels test (Version 2.05.). Swansea: Lognostics. 
Moyer, A. (2013). Foreign accent: The phenomenon of non-native speech. Cambridge: Cambridge University Press.

Nobre-Oliveira, D. (2007). The effect of perceptual training on the learning of English vowels by Brazilian Portuguese speakers. [Unpublished Doctoral Dissertation]. Universidade Federal de Santa Catarina, Brazil.

Piske, T. (2007). Implications of James E. Flege's research for the foreign language classroom. In O.-S. Bohn, \& M. Munro (Eds.), Language experience in second language speech learning - In honor of James Emil Flege (pp. 301-14). Amsterdam/ Philadelphia: John Benjamins Publishing Company.

Piske, T., MacKay, I., \& Flege, J. (2001). Factors affecting degree of foreign accent in an L2: a review. Journal of Phonetics, 29, 191-215.

Rato, A. (2014). Effects of perceptual training on the identification of English vowels by native speakers of European Portuguese. Concordia Working Papers in Applied Linguistics, 5, 529-546.

Rato, A. (2018). Perceptual categorization of English vowels by native European Portuguese speakers. In A. Rato \& S. Lima (Eds.) LinguíStica - Estudos Experimentais sobre o Português, 14 (2), 61-80.

Rato, A., \& Rauber, A. (2015). The effects of perceptual training on the production of English vowel contrasts by Portuguese learners. In Proceedings of ICPhS 2015. University of Glasgow, Glasgow, UK. http://www.icphs2015.info/pdfs/ proceedings.html.

Rato, A., Rauber, A., Soares, L., \& Lucas, L. (2014). Challenges in the perception and production of English front vowels by native speakers of European Portuguese. Diacrítica - série ciências da linguagem, 28(1), 137-155.

Rauber, A. S. (2010). Acoustic characteristics of Brazilian English vowels: perception and production results. Saarbrücken: Lambert Academic Publishing.

Rauber, A. S., Escudero, P., Bion, R., \& Baptista, B. (2005). The interrelation between the perception and production of English vowels by native speakers of Brazilian Portuguese. In Proceedings of Interspeech 2005 (pp. 2913-2916).

Rauber, A. S., Rato, A., Silva, A. (2010). Percepção e produção de vogais anteriores do inglês por falantes nativos de Mandarim. Diacrítica, 24(1), 5-23.

Rauber, A., Rato, A., Kluge, C., \& Santos, G. (2012). TP, Version 3.1. [Software] http:// www.worken.com.br/tp

Roach, P. (2004). English phonetics and phonology (4th ed.). Cambridge: Cambridge University Press.

Solé, M.J. (2013). Phonological vs lexical categories in an L2. In Proceedings of the 6th Phonetics and Phonology in Iberia Conference (pp.58-59). Lisbon, Portugal: Lisbon University.

Strange, W. (2007). Cross-language phonetic similarity of vowels: Theoretical and methodological issues. In O.-S. Bohn, \& M. Munro (Eds.), Language experience in second language speech learning - In honor of James Emil Flege (pp. 35-55). Amsterdam/Philadelphia: John Benjamins Publishing Company.

Weber, A., \& Cutler, A. (2004). Lexical competition in non-native spoken-word recognition. Journal of Memory and Language, 50(1), 1-25. 


\section{APPENDIX A}

Table 1. List of stimuli

\begin{tabular}{|c|c|c|}
\hline vowels & real words & pseudo words \\
\hline /i:/ & $\begin{array}{l}\text { feed } \\
\text { feet }\end{array}$ & $\begin{array}{l}\text { jeed } \\
\text { jeet } \\
\text { veep }\end{array}$ \\
\hline$/ \mathbf{I} /$ & $\begin{array}{l}\text { bid } \\
\text { bit }\end{array}$ & \begin{tabular}{|l} 
jid \\
jit \\
vib
\end{tabular} \\
\hline $\mid \varepsilon /$ & $\begin{array}{l}\text { bed } \\
\text { pet }\end{array}$ & \begin{tabular}{|l} 
jeb \\
veck \\
veg
\end{tabular} \\
\hline$/ \mathfrak{a} /$ & $\begin{array}{l}\text { cab } \\
\text { cap }\end{array}$ & \begin{tabular}{|l|} 
zad \\
zat \\
vab \\
\end{tabular} \\
\hline /3:/ & $\begin{array}{l}\text { heard } \\
\text { hurt }\end{array}$ & $\begin{array}{l}\text { jerd } \\
\text { jurb } \\
\text { jurp }\end{array}$ \\
\hline $\mid \mathbf{A} /$ & $\begin{array}{l}\text { pub } \\
\text { pup }\end{array}$ & $\begin{array}{l}\text { vub } \\
\text { zud } \\
\text { zut }\end{array}$ \\
\hline $\begin{array}{l}\text { / a:/ } \\
\text { (filler) }\end{array}$ & $\begin{array}{l}\text { bark } \\
\text { tart }\end{array}$ & $\begin{array}{l}\text { parsh } \\
\text { barsh }\end{array}$ \\
\hline
\end{tabular}


